\title{
Rituales con restos humanos en ámbito ilergete: reflexiones a partir de las evidencias de EI Molí d’Espígol (Tornabous, Lérida)*
}

\author{
Rituals involving human remains in the Ilergetan area: some reflections from the \\ El Molí d'Espígol evidence
}

\author{
Jordi Principal $^{a}$ y M. Eulàlia Subirà de Galdàcano ${ }^{b}$
}

A Joan B. López Melcion, in memoriam

\begin{abstract}
RESUMEN
El Molí d'Espígol es el hábitat ibérico más destacado del territorio histórico del pueblo ilergete. El estudio de los restos humanos ya anteriormente conocidos, sumado a la identificación de nuevas evidencias, ha permitido no solo aumentar el elenco de las inhumaciones perinatales del asentamiento, sino también confirmar la existencia de restos humanos de adulto. A partir del estudio de síntesis sobre la presencia de restos humanos en contextos de hábitat hallados en el territorio histórico de los Ilergetes, se plantea la significación social de tales prácticas en el ámbito de dicho pueblo ibero.
\end{abstract}

\begin{abstract}
El Moli d'Espigol is the most important Iberian site within the historical territory of the Ilergetes. A critical Anthropological study of the already known human remains, as well as the discovery of new material coming from recent excavations conducted at the site, has resulted not only in an increase of the perinatal burials, but also in the identification of bone fragments belonging to adult individuals. Synthesis of the evidence coming from the Ilergetan territory permits us to advance some hypotheses on the social meaning of those practices among this Iberian people are advanced.
\end{abstract}

Palabras clave: Restos humanos; Íberos; Primera Edad del Hierro; Paleoantropología; El Molí d'Espígol; Ilergetes; península ibérica.

Key words: Human remains; Iberians; Early Iron Age; Paleoanthropology; El Moli d'Espígol; Ilergetes; Iberian peninsula.

\section{INTRODUCCIÓN}

La existencia de restos humanos en El Molí d'Espígol se conoció gracias al primer estudio sobre el hallazgo puntual de dos inhumaciones perinatales (Cura 1989; Mercadal 1989). Tal noticia incluía el hábitat en la problemática general de esta práctica como el primero y único en presentar evidencias de este tipo en el área ibérica ilergete. Las ulteriores campañas de excavación aumentaron esta cifra hasta cuatro (Cura 1989, 2006: 37; Escala et al. 2016: 276-278), aunque el avance de la investigación en la depresión central catalana, muy especialmente en la fortaleza de Els Vilars (Junyent y López Melcion 2016), ha sobrepasado cualquier expectativa en relación con dicha temática (cf. infra).

A partir de finales de los años 90 diferentes trabajos sobre prácticas rituales en el mundo ibérico catalán o sobre la problemática de las "cabezas cortadas" ( $c f$. infra) reiteran la presencia en El Molí d'Espígol de

* El Servei d'Arqueologia i Paleontologia de la Generalitat de Catalunya financió las dataciones radiocarbónicas AMS (UBAR-1039/1040 y CNA-2980.1.1)

a Museu d'Arqueologia de Catalunya. Passeig de Santa Madrona 39-41. 08038 Barcelona. Correo e.: jprincipal@gencat.cat https://orcid.org/0000-0001-9030-4427.

${ }^{\mathrm{b}}$ Grup de Recerca Aplicada al Patrimoni Cultural (GRAPAC). Unitat d'Antropologia Biològica, Dept. de Biologia Animal, Biologia Vegetal i Ecologia, Universitat Autònoma de Barcelona. 08193 Bellaterra. Correo e.: eulalia.subira@uab.cat https://orcid.org/0000-0001-5315-0051.

Recibido 25-III-2020; aceptado 9-IX-2020. 


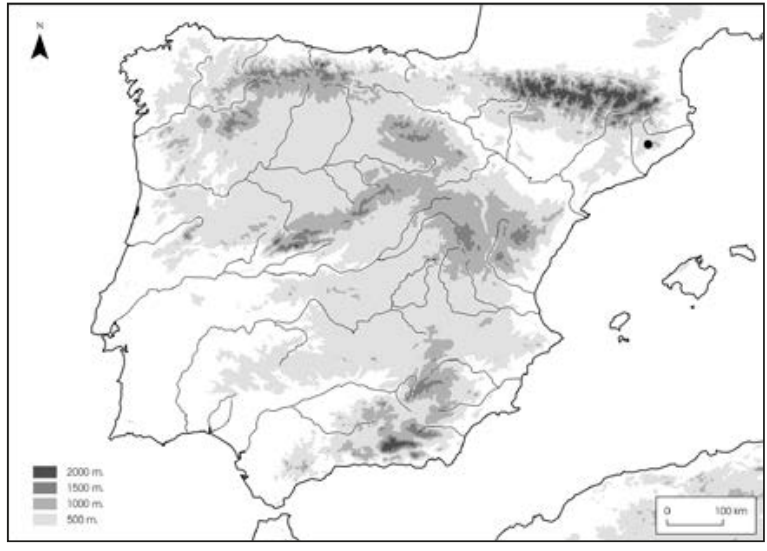

Fig. 1. Situación del hábitat de El Molí d'Espígol (Tornabous, Lérida) en la península ibérica.

restos craneales humanos (Sanmartí 1994: 344; Belarte y Sanmartí 1997: 16-17; Rovira Hortalà 1998: 168, fig. 1.6) ${ }^{1}$. Su atribución o existencia se mantenía en suspenso ya que tales restos nunca fueron publicados ni tampoco información alguna sobre su contexto de aparición. Ello no ha impedido incluir El Molí d'Espígol en el elenco de yacimientos con evidencias del ritual de exposición de "cabezas cortadas", detectado en el área layetano-indigete, trasladando su expresión física y sentido social también al mismo ( $c f$. infra).

Sin embargo, la revisión de los datos antropológicos disponibles en la actualidad, procedentes de antiguas excavaciones y nuevas campañas, además de incrementar la cifra de las inhumaciones perinatales del yacimiento, ha confirmado la existencia de restos atribuibles a individuos adultos. Todo ello resitúa El Molí d'Espígol en un espacio central en relación con el estudio de tales problemáticas $\mathrm{y}$, sobre todo, en relación con su sentido y proyección en el área ibérica ilergete.

\section{EL MOLÍ D'ESPÍGOL, DE FORTALEZA PREIBÉRICA A CIUDAD ILERGETE}

El yacimiento se encuentra en el extremo norte de la llanura del Urgell, en el término municipal de Tornabous (Lérida), a unos $1700 \mathrm{~m}$ al noreste del casco urbano de la población actual (UTM31N/ETRS89 E 339617 , N 4619235) (Fig. 1). Dispone, además, de la máxima protección legal en el ámbito patrimonial: Bien Cultural de Interés Nacional desde 2009². El Molí d'Espígol es el asentamiento ibérico más extenso (c. 5 ha) e impor-

\footnotetext{
1 La noticia se debe a una comunicación personal de M. Cura ( $c f$. Sanmartí 1994: 344, n. 70), responsable científico del yacimiento durante el período 1987-1994 (cf. Principal et al. 2019: 199, n. 5).

2 BOE núm. 82, 04.04.2009, sec. III. 32429-32433.
}

tante, conocido hasta el momento, del territorio histórico de los Ilergetes (Fatás 1987; Sanmartí y Santacana 2005: 36; Salinas de Frías 2010: 70-71). Destaca por: (a) su amplia cronología; (b) unas dimensiones que rebasan el patrón del área ilergete; (c) un urbanismo "ortogonal" con calles anchas y edificios "singulares"; (d) un espacio suburbano muy bien definido; y (e) la monumentalidad y complejidad de sus sistemas defensivos.

Se trata de un asentamiento de larga duración. Se funda durante la Primera Edad del Hierro (finales del siglo VIII a. n. e.) (Principal 2007; Principal et al. 2010, 2019: 206), se expande y consolida durante toda la época ibérica y se abandona hacia el 200 a. n. e. con una breve reocupación casi un siglo más tarde (Principal et al. 2010, 2019: 214-221). Su extensión y longevidad son factores decisivos a la hora de entender su organización, caracterizada por un urbanismo complejo en constante crecimiento (Fig. 2).

El Molí d'Espígol, en el momento de su fundación en la Primera Edad del Hierro, tiene unas potentes defensas, una sólida muralla torreada (MUR-1) con un posible foso, y un hipotético campo frisio (Principal et al. 2010; 2019: 200-203), al estilo de lo documentado en la fortaleza de Els Vilars (Junyent y López Melcion 2016). Los espacios y los equipamientos asociados son los típicos de este momento: estructuras rectangulares polifuncionales, domésticas y de trabajo con divisiones internas, banquetas y hogares, alguno en forma de lingote chipriota (Principal et al. 2019: 206-208). Destaca un espacio religioso exterior diferenciado y con cierta monumentalidad, asociado a una de las torres (T-4) de la muralla, y formado por cuatro betilos (Principal et al. 2019: 203-206).

Durante el período Ibérico Antiguo se amplía el asentamiento con un nuevo sistema defensivo y una innovadora planificación urbanística. Delimita su perímetro una muralla lisa (MUR-2) de aparejo en emplecton sin bastiones o torres, y muy probablemente con un foso. Se constata la continuidad del hábitat y las estructuras de la Primera Edad del Hierro durante los estadios iniciales del período Ibérico Antiguo (Principal et al. 2019: 208-214).

El sitio alcanza su momento de máximo esplendor en el período Ibérico Pleno. Se remodela y amplía otra vez mediante un nuevo y sofisticado perímetro defensivo (MUR-3) con un foso asociado, la monumentalización de accesos, un urbanismo complejo, unos espacios de uso colectivo bien delimitados, infraestructuras urbanas, barrios suburbanos manufactureros y espacios de almacenaje (Principal et al. 2012; Sala et al. 2013; Principal et al. 2019: 214-220). El final de esta fase se dataría en torno al 200 a. n. e.

Por último, después de un hiato de casi 75 años, durante el período Ibérico Tardío, se localiza una ocupación en la zona norte y noreste con un hipotético nuevo plan- 


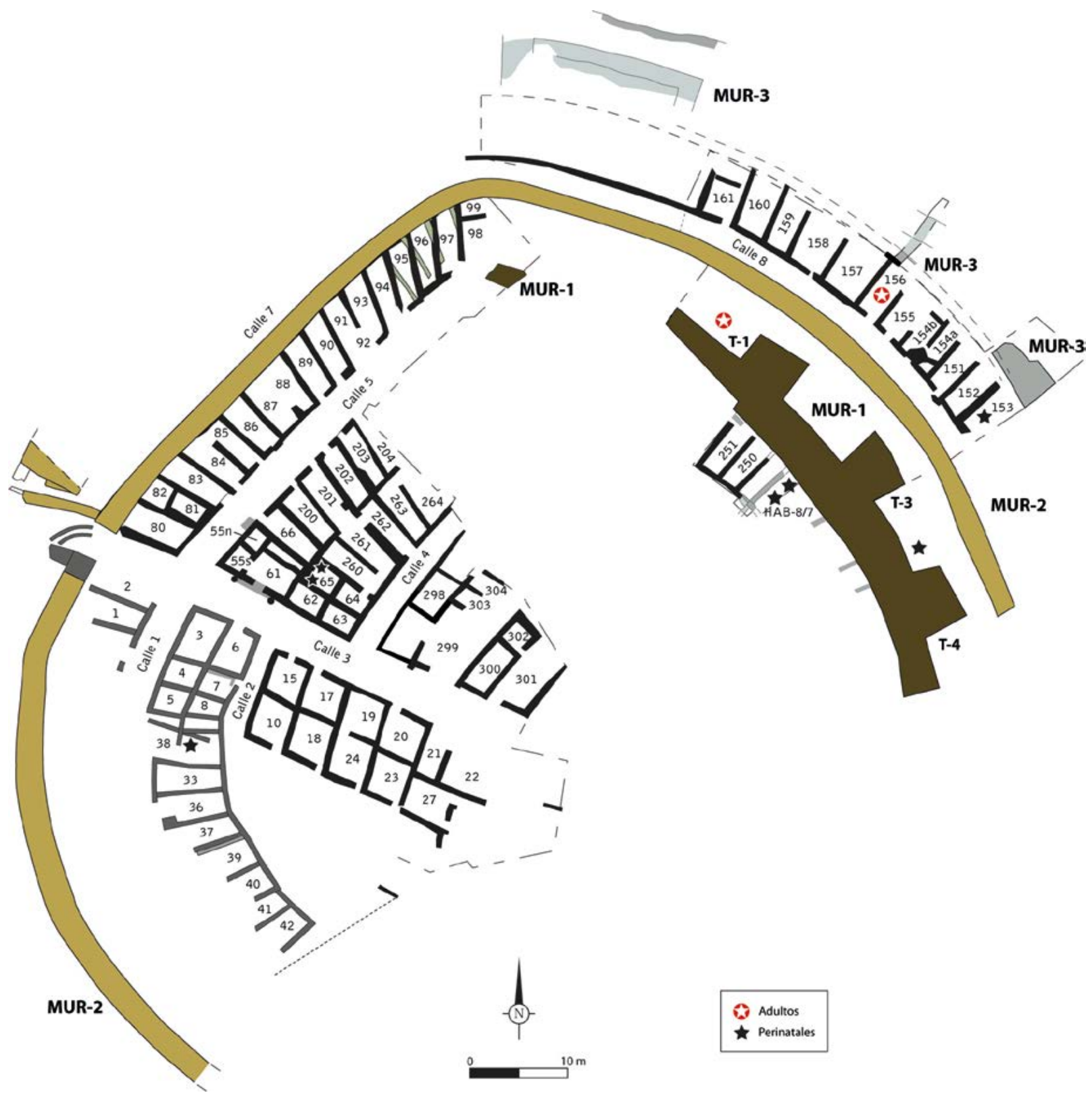

Fig. 2. Planta de El Molí d'Espígol con la localización de los lugares en que se hallaron de los diferentes restos estudiados en el texto. En color en la edición electrónica.

teamiento urbanístico. El final de esta fase marca el abandono definitivo del sitio (Principal et al. 2019: 221).

\section{LAS EVIDENCIAS ANTROPOLÓGICAS}

Las evidencias detectadas hasta el momento pertenecen tanto a individuos adultos como a infantiles, mayoritarios estos últimos. En conjunto, su cronología es tan amplia como la del mismo yacimiento (mediados del siglo VII-finales del III a. n. e.). Tras su estudio morfológico (aspectos tafonómicos y patológicos), se ha calculado un índice de preservación basado en el cálculo establecido por Walker et al. (1988) que permite conocer la representatividad de las distintas regiones anatómicas en función del recuento de huesos largos, cinturas y cráneo. El diagnóstico de edad (Scheuer y Black 2000; Campillo y Subirà 2004) se 
ha establecido a partir de las medidas descritas por Kósa (1989) y Scheuer y Black (2000), y el grado de desarrollo dental recogido por Crétot (1978) y Ubelaker (1989). Para el diagnóstico del sexo (mandíbula e ilion) se han utilizado los criterios de Schutkowski (1993). En los dos únicos fragmentos de individuos adultos solo se ha realizado el estudio macroscópico y morfológico al no ser piezas diagnósticas.

\subsection{Los restos de individuos adultos}

El Individuo 1 (INDa-1): fue hallado en un sondeo de comprobación en el nivel de fundamentación de la cortina de la muralla MUR-1 (UE 11044), entre las torres T-1 y T-2. Se trata de un relleno constructivo homogéneo y sin contaminaciones entre la muralla y la escarpa del foso. Como no se excavó en extensión, cabe la posibilidad de que se hallen más restos en caso de continuar o completar la excavación del nivel, y que no sea un ítem aislado. La cortina se edificó en una segunda fase constructiva del complejo de la muralla MUR-1 (Principal et al. 2019: 200-201), situable a mediados/segunda mitad del siglo VII a. n. e.

La datación radiocarbónica realizada sobre diferentes restos de fauna de dicha unidad estratigráfica dio como resultado una fecha imprecisa entre el 758415 a. n. e. (Tab. 1.1). Desgraciadamente, esta datación entre mediados del siglo VIII y finales del $\mathrm{V}$ a. n. e., enmarcada en la llamada "catástrofe de la Edad del Hierro", resulta demasiado amplia. Con todo, es coherente con la datación arqueológica a partir del registro cerámico ya que el intervalo de tiempo de la cerámica representa tan solo una pequeña porción dentro del amplio intervalo de probabilidad de la verdadera fecha calibrada. Así pues, la

\begin{tabular}{|c|c|c|}
\hline Muestra & Datación $\mathbf{C}^{14}$ & $\begin{array}{l}\text { Fecha calibrada } \\
(2 \sigma)\end{array}$ \\
\hline 1. UBAR-1039/1040 & $2465 \pm 33 \mathrm{BP}$ & $\begin{array}{c}\text { cal BC } 758-683 \\
-28,2 \% \\
\text { cal BC } 670-482 \\
-56,8 \% \\
\text { cal BC } 467-415 \\
\quad-10,4 \%\end{array}$ \\
\hline 2. CNA 2980.1.1 & $2535 \pm 33 \mathrm{BP}$ & $\begin{array}{c}\text { cal BC } 799-730 \\
-39,9 \% \\
\text { cal BC } 692-659 \\
-14 \% \\
\text { cal BC } 652-543 \\
-46 \%\end{array}$ \\
\hline
\end{tabular}

Tab. 1. El Molí d’Espígol (Tornabous, Lérida). Dataciones radiocarbónicas, calibración $2 \sigma$ (Reimer et al. 2013).

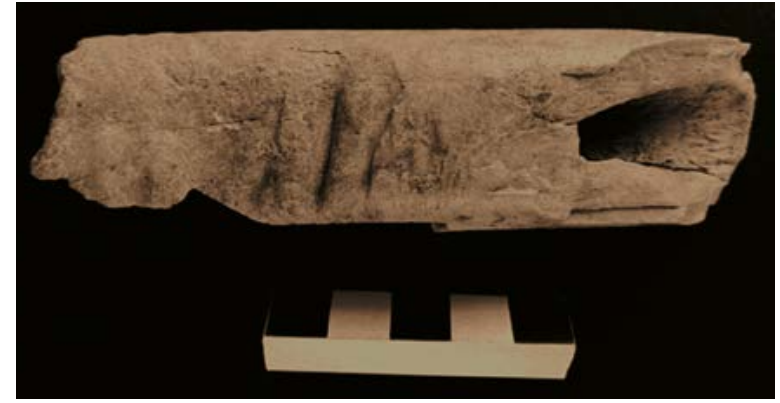

Fig. 3. El Molí d'Espígol (Tornabous, Lérida): Individuo adulto 1 (INDa-1), tercio distal de fémur izquierdo humano en el que se observan marcas de corte paralelas En color en la edición electrónica.

hipótesis de una cronología de mediados/segunda mitad del siglo VII a. n. e. para la formación del depósito resulta del todo factible.

Se conserva de este primer individuo un fragmento de diáfisis del tercio distal del fémur izquierdo. Mide $112 \mathrm{~mm}$ de longitud, $90 \mathrm{~mm}$ de circunferencia y 32 y $23 \mathrm{~mm}$ de diámetro máximo transverso y anteroposterior respectivamente (Fig. 3). Su extremo proximal fue cortado cuando el hueso todavía conservaba colágeno, tal y como se evidencia por la extracción de parte de la cortical del hueso y la morfología redondeada de los bordes del propio corte. El impacto, perpendicular al hueso, afectó su parte posterior y levantó la lasca al alcanzar la región anterior. En cambio, la sección del fragmento cercana a la epífisis distal se realizó sobre el hueso en estado seco, cuando ya no conservaba materia orgánica, tal como muestran los bordes de fractura lineal. En su lado posterior se observa una fractura reciente que es la única zona del hueso sin pátina de rodamiento.

A lo largo de la diáfisis se observan marcas transversales de corte, en su mayoría paralelas entre sí realizadas hace tiempo. Varía su longitud, profundidad y grado de desgaste a lo largo de la pieza menor en la región proximal. Se hicieron desde un plano ligeramente inclinado, de abajo a arriba, por un elemento cortante al que se le imprimió una fuerza contundente, salvo en la región medial donde hay otras marcas más superficiales.

El Individuo 2 (INDa-2) fue hallado en el segundo nivel de ocupación (UE 20021) del sector 156 (complejo UH/M 16), datado durante la primera mitad/ mediados del siglo III a. n. e. (Cura 2006: 39-40). Todo parece indicar que corresponderían a este fragmento las noticias publicadas desde fines de los años 1990 (cf. supra) sobre la existencia de restos de cráneo humano en el yacimiento.

Las UH/M (unidades de habitación/almacén) de El Molí d’Espígol son complejos “domésticos” formados 


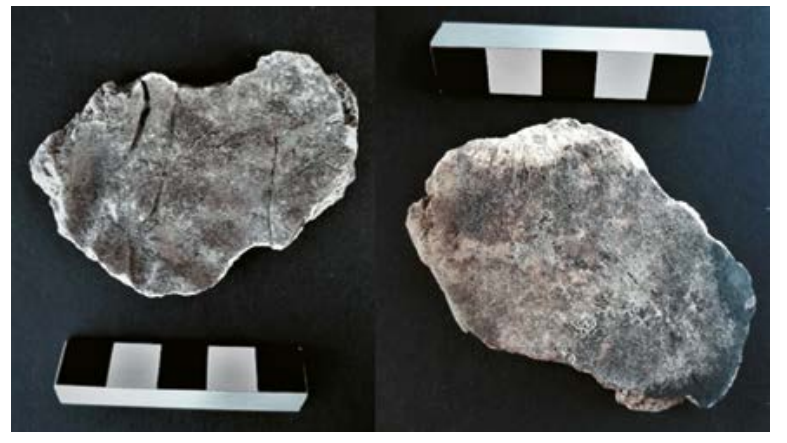

Fig. 4. El Molí d'Espígol (Tornabous, Lérida): Individuo adulto 2 (INDa-2), fragmento de parietal izquierdo humano. Parte superior por la cara exocraneal, parte inferior por su cara endocraneal.

por tres módulos rectangulares. Dos conformarían una unidad con una puerta de acceso al exterior, mientras el tercero, mucho menor, sería independiente con su propia puerta de acceso al exterior y sin comunicación aparente con los otros dos. La parte compartimentada correspondería al espacio de habitación, doméstico, y el módulo independiente sería un almacén cuyo registro de cultura material, en general, es mucho más rico que el del espacio mayor (Belarte 1997: 143; Cura 2006: 32).

El sector 156 es una de las estancias que, junto con los sectores 157-158, forma el complejo UH/M 16 del barrio extramuros septentrional (Cura 2006: 39-40), construido a inicios del siglo IV a. n. e. El sector 156 habría actuado como "espacio de almacenaje", independiente del módulo formado por los sectores 157 158. Este sector ocupa un lugar central respecto del espacio abierto, público, que se abre justo delante de él. A partir de los pocos datos del registro de excavación conservados, sabemos que sufrió un incendio a finales del siglo III a. n. e.

Se conserva de este segundo individuo un fragmento de parietal izquierdo de 65 x $46 \mathrm{~mm}$ (Fig. 4). Su límite, en la región posteroinferior, es el ángulo de la mastoides que articula con el temporal. En su parte posterior conserva el borde de una porción de la sutura lambdoidea [L3] y parietotemporal. En la región anterior y superior el límite es una fractura antigua y en la región inferior el borde de la escama del temporal y una fractura de carácter reciente.

La cara endocraneal muestra parte del surco transverso y del surco de las meníngeas medias y la exocraneal alteración térmica en la región anterior. En esta región, el hueso está fracturado por lo que se aprecia que el fuego solo alcanzó la tabla externa del diploe. Ello indica que fue un suceso ocasional y no intencional que no se prolongó en el tiempo y mucho menos afectó a todo el cráneo.

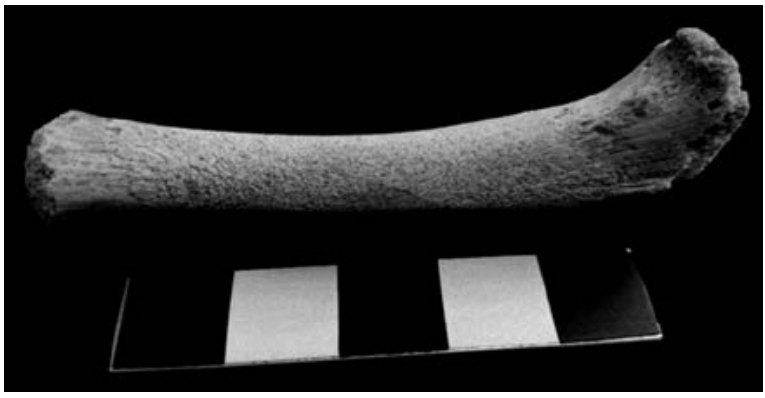

Fig. 5. El Molí d'Espígol (Tornabous, Lérida): Individuo infantil 1 (INDi-1), tibia izquierda humana en la que se observa periostitis a lo largo de la diáfisis.

\subsection{Los restos de individuos infantiles}

El INDi-1 fue el único resto humano documentado en la UE 24033. Procede de un pequeño sondeo en un estrato, interpretado como un nivel de regularización constructiva del pavimento SL 24022 de la habitación HAB-8, asignado a la primera fase de ocupación de El Molí d'Espígol, durante la Primera Edad del Hierro. Desconocemos la fisonomía completa de la HAB-8, pero podría haberse tratado de una estancia de dimensiones notables (c. $3 \mathrm{~m}$ de ancho), donde destaca un hogar en forma de lingote chipriota (LL 24026) (Principal et al. 2019: 206-207). Durante el proceso de excavación no se detectó ninguna fosa ni estructura negativa que sugiriera la existencia de una inhumación infantil. Como el sondeo no alcanzó la totalidad de la estancia hay que suponer que el resto pertenece a una inhumación ubicada más allá de alguno de los límites de la excavación. Se nos antoja una hipótesis menos probable, en función de la misma dinámica del yacimiento, pero tampoco descartable, que fuera un resto aislado, vinculable a una acción precedente, y víctima del movimiento de tierras motivado por la regularización constructiva. Incluso cabe pensar en algún tipo de desplazamiento de su lugar original por la acción de algún pequeño roedor: de hecho, la pieza está mordisqueada.

La secuencia estratigráfica indica que su datación es anterior a la construcción de la HAB-7 ( $c f$. infra), lo cual nos llevaría a pensar en una cronología dentro del siglo VII a. n. e., quizá dentro de la primera mitad de la centuria.

Este individuo infantil INDi-1 está representado por una única tibia izquierda (índice de preservación del 4,54 \%), con la epífisis distal mordisqueada y, posiblemente también, la proximal (Fig. 5). Mide unos $63 \mathrm{~mm}$ de longitud. Ello, junto a la comparación con tibias de diversos individuos perinatales de edades conocidas del Laboratori d'Antropologia Biològica de la Universitat Autònoma de Barcelona, permite aproxi- 
mar su edad de muerte entre las 38-40 semanas de vida intrauterina, y por tanto en torno al nacimiento. La ausencia de otras piezas óseas no permite un diagnóstico de sexo del individuo. El hueso presenta periostitis a lo largo de su cara medial.

El INDi-2 estaba enterrado en una fosa ovoide (EN 24037), sin ajuar, practicada en el pavimento SL 24008 de la habitación HAB-7. Se situaba en el ángulo noreste de la pieza, seguramente en relación con la remodelación del espacio y el inicio de una nueva fase de ocupación que marca el pavimento: presenta un hogar en contacto con la pared norte de la pieza, y un par de agujeros de poste seguramente destinados a soportar un altillo. La HAB-7 corresponde a la última fase de ocupación de la fortaleza de la Primera Edad del Hierro, la cual amortiza los restos de la HAB-8 (cf. supra) (Principal et al. 2019: 207-208).

La datación radiocarbónica realizada con las tibias de este individuo dio como resultado una fecha calibrada entre 799-543 a. n. e. (Tab. 1.2), de nuevo en el espacio temporal de la "catástrofe de la Edad del Hierro". Con todo, de forma preliminar y de manera coherente con el contexto arqueológico, pensamos que la acción podría situarse, grosso modo, durante el siglo VII a. n. e.

Armentano y Nociarová ${ }^{3}$ estudiaron al INDi-2. En su trabajo describían los restos como pertenecientes a un individuo muy bien representado $(86,4 \%$ de índice de preservación). En la actualidad la preservación es menor por la destrucción de las dos tibias para la datación (Fig. 6B). Las autoras sugerían que fuera el depósito primario de un bebé a término si bien el grado de desarrollo del segundo incisivo deciduo inferior derecho permitiría asignarle una edad un poco mayor, siempre inferior a cuatro meses. Se atribuía a un individuo de sexo femenino por la morfología del hueso coxal. La revisión de los materiales para el presente trabajo permite reafirmar este diagnóstico a partir de la morfología de la mandíbula, y también su edad de muerte que oscilaría entre las 38-40 semanas de gestación y los 2 meses de vida y por tanto posterior al nacimiento (grado de desarrollo del incisivo y del resto de piezas esqueléticas, toma de distintas medidas del esqueleto craneal y postcraneal). Ninguna evidencia en los huesos indica la causa de la muerte, aunque algunos presentan una periostitis generalizada, que algunos autores consideran propia del desarrollo del individuo y otros atribuyen a un proceso infeccioso que podría provocarla. A nivel tafonómico, el antebrazo (Fig. 6B) y la clavícula derecha, así como ambos fémures presentan mordeduras, posiblemente de roe-

\footnotetext{
${ }^{3}$ N. Armentano y D. Nociarová. "Estudi antropològic de les restes procedents del Molí d'Espígol (Tornabous, Urgell)”. Informe inédito. Antropòlegs Lab. Barcelona, 2015.
}

dor. Su presencia en la fosa justificaría los desplazamientos de algunas conexiones anatómicas observadas entre los huesos durante la excavación.

Los restos del INDi-3 proceden del relleno (UE 10104) de una trinchera de expolio para extraer piedra de la muralla MUR-1. Por la secuencia contextual y el material asociado, el depósito se habría formado durante la segunda mitad del siglo VI a. n. e. El relleno de las trincheras y fosas de expolio se realizó presumiblemente con tierra y restos procedentes de otras partes del yacimiento o de espacios cercanos con fases previas, ya amortizadas, del hábitat. Ello parece indicar que los huesos procedían de sedimentos aportados y, en consecuencia, que su ubicación era secundaria y descontextualizada. De ser cierta esta hipótesis, el material podría corresponder a una cronología primaria de Primera Edad del Hierro (siglo VII a. n. e.) o del inicio del Ibérico Antiguo (primera mitad del siglo VI a. n. e.).

El INDi-3 solo está representado por la extremidad inferior izquierda: $2 / 3$ distales del fémur y $2 / 3$ distales de la tibia (índice de preservación de 9,09\%) (Fig. 6D). Los dos extremos del fémur están mordidos. La rotura del borde proximal de la tibia es reciente mientras que la leve erosión del extremo distal también podría corresponder a mordeduras. Las distintas dimensiones de las mordeduras del fémur y de la tibia sugieren la actuación de dos especies. Los restos carecen de evidencias de patología ósea. La ausencia de piezas diagnósticas impide la atribución de sexo y su estado incompleto no permite aproximar la edad de muerte más allá de su condición de individuo perinatal.

Los restos del INDi-4 proceden de la excavación de un pequeño sondeo practicado en el sector 38 , siguiendo la pared de cierre occidental. La UE 18160 en que apareció se ha identificado con un estrato de relleno/preparación para la construcción de un piso datado durante el período Ibérico Pleno (siglos IV-III a. n. e.). Como en el caso del INDi-1 (cf. supra), durante la excavación no se distinguieron estructuras negativas que indicaran una pequeña fosa o agujero. Es decir, los datos disponibles en la actualidad impiden determinar objetivamente si es una deposición primaria, aunque el contexto podría llevar a considerarlo un enterramiento en espacio doméstico. Al ser un sondeo reducido no es descartable la aparición de más restos si se excavara toda la superficie del sector.

El sector 38 forma parte con el 33 y 36 de la UH/M 11, ubicada en la zona 18, el barrio que delimita la gran plaza por el sur. Al tratarse de la mitad norte del módulo dividido en dos (sectores 33 y 38 ) era una de las partes que configuraban el espacio de habitación/doméstico de la UH/M 11 (Cura 2006: 35). 


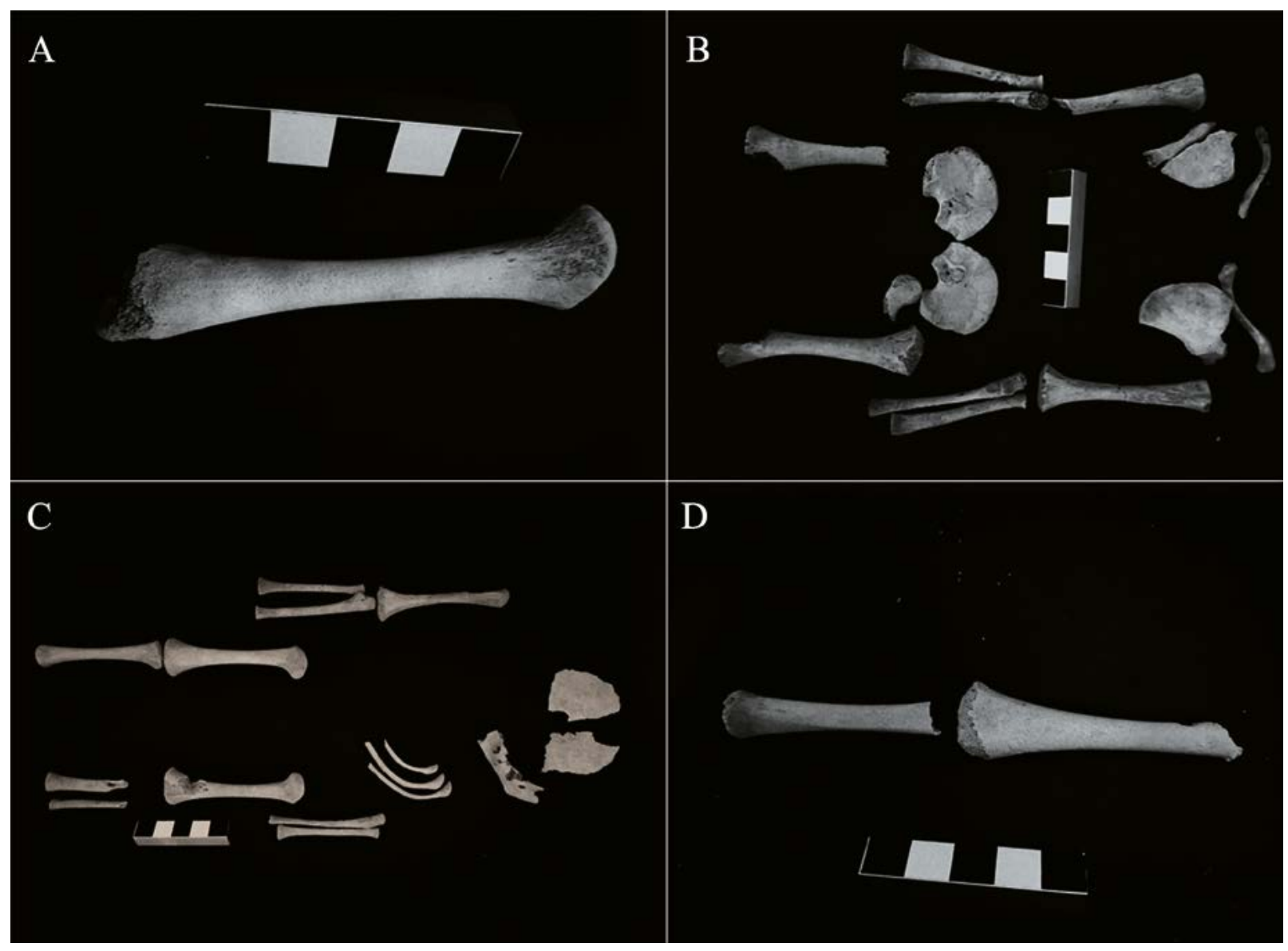

Fig. 6. INDi-4, A (parte superior izquierda); INDi-2, B (parte superior derecha de la imagen); INDi-5, C (parte inferior izquierda); INDi-3, D (parte inferior derecha).

El INDi-4 cuenta solo con un fémur izquierdo (índice de preservación del $4,54 \%$ ) cuya epífisis distal muestra evidencias de mordedura (Fig. 6A). Al estar incompleto su longitud solo puede indicar el umbral inferior de su edad en el momento de la muerte: más de dos meses de vida postnatal. Faltan elementos para realizar un diagnóstico del sexo, así como evidencia de patología ósea.

El INDi-5 y el INDi-6 fueron hallados en el sector 65 , una de las estancias que conforman la parte oriental del Edificio Singular A (ES-A) (Cura 1989: 177; Mercadal 1989). Ambos fueron practicados en el mismo pavimento SL 15214, junto a la pared norte. El enterramiento EN 15212 (INDi-5) ${ }^{4}$ se encontró en el ángulo noroeste del sector, en muy mal estado, sin ajuar. No se pudo determinar la morfología de la sepultura. El enterramiento EN 15213 (INDi-6) apa-

${ }^{4}$ Mercadal (1989) lo enumera como individuo 1 y al INDi-6 como individuo 2 reció a $1,2 \mathrm{~m}$ al este de EN 15212. Su cabeza se orientaba al este, en decúbito prono. Estaba depositado en una pequeña fosa ovalada sin material de acompañamiento o ajuar. Tampoco se ha podido determinar si las deposiciones fueron simultáneas o sucesivas; sólo es posible concluir que los enterramientos se realizaron durante, o a lo largo de una misma fase de ocupación, que pudo haber durado unos 50 años. El nivel en que fueron hallados corresponde a la fase III del ES-A, datada en la primera mitad del siglo III a. n. e. (Monrós 2010: 214). En este momento, los sectores 65 al oeste y 64 al este formarían una misma unidad estructural, sin que se hayan detectado enterramientos en el 64. El material recuperado en la excavación de esta estancia permite inferir que era un espacio peculiar, de cierta excepcionalidad y prestigio. El registro cerámico era pobre pero aparecen restos de enlucido parietal policromado, cáscaras de huevo, utillaje metálico, un silbato de hueso, dos mandíbulas de ovicaprino y un maxilar 
de équido, además de los dos enterramientos infantiles (Monrós 2010: 217).

En conclusión, se ha propuesto que el espacio de los sectores 65/64, donde se hallaron los enterramientos, hubiera revestido un carácter ritual dentro del complejo del ES-A, interpretado como un espacio de reunión de las élites de la comunidad, así como de residencia de un grupo familiar destacado dentro del entramado social y económico de la ciudad ibérica, (Monrós 2010: 219).

El INDi-5 apareció como un depósito primario en posición fetal (Mercadal 1989). La preservación de este individuo infantil es del 54,54\%. Conserva básicamente las extremidades inferiores y superiores (Fig. 6C). Se han recuperado dos fragmentos craneales y la hemimandíbula izquierda con las coronas dentales deciduas de los dos primeros incisivos (71 y 72), un tercio del canino y primer molar (73 y 74). Ello correspondería a una edad dental estimada en unas 40 semanas de gestación que coincidiría con la calculada a partir de la longitud de los huesos largos (Mercadal 1989). El reestudio actual de la morfología de la hemimandíbula parece indicar que era una niña. Presenta evidencias de mordeduras, en este caso, en el cúbito izquierdo.

Según Mercadal (1989) el INDi-6 se dispuso en decúbito prono. Conserva el cráneo, cintura escapular y tronco (índice de preservación del 31,82 \%) (Fig. 7A). La representatividad del esqueleto es baja pero es el que conserva mayor número de piezas dentales. Gracias a ellas la atribución de su edad es mas precisa: el maxilar conserva las coronas enteras de las dos incisivas derechas $(61,62)$, media corona del primer molar (64) y un tercio del segundo (65); de la mandíbula se conservan las coronas enteras de las dos incisivas derechas $(81,82)$, media corona de ambos primeros molares $(74,84)$ y un tercio de la corona de los segundos molares $(75,85)$. Mercadal estableció la edad de muerte entre las tres semanas y un mes postnatal sin hacer una atribución del sexo. Este estudio, basándose en el desarrollo dental de las piezas, concreta la edad en unas 40 semanas de gestación. La morfología de la hemimandíbula parece indicar que era de sexo masculino. No hay evidencia de patología en los restos.

El Individuo INDi-7 se documentó en el sector 153 (Cura 2006: 37). Se ignoran las circunstancias concretas del hallazgo, su ubicación en la estancia, la morfología del sepulcro o las características de la deposición. El único detalle registrado es que el enterramiento apareció bajo una losa, resto de la pavimentación de la estancia durante la segunda mitad del siglo III a. n. e. Hemos de suponer que la deposición ocurrió durante las obras de remodelación que marcaban el inicio de una nueva fase de ocupación,
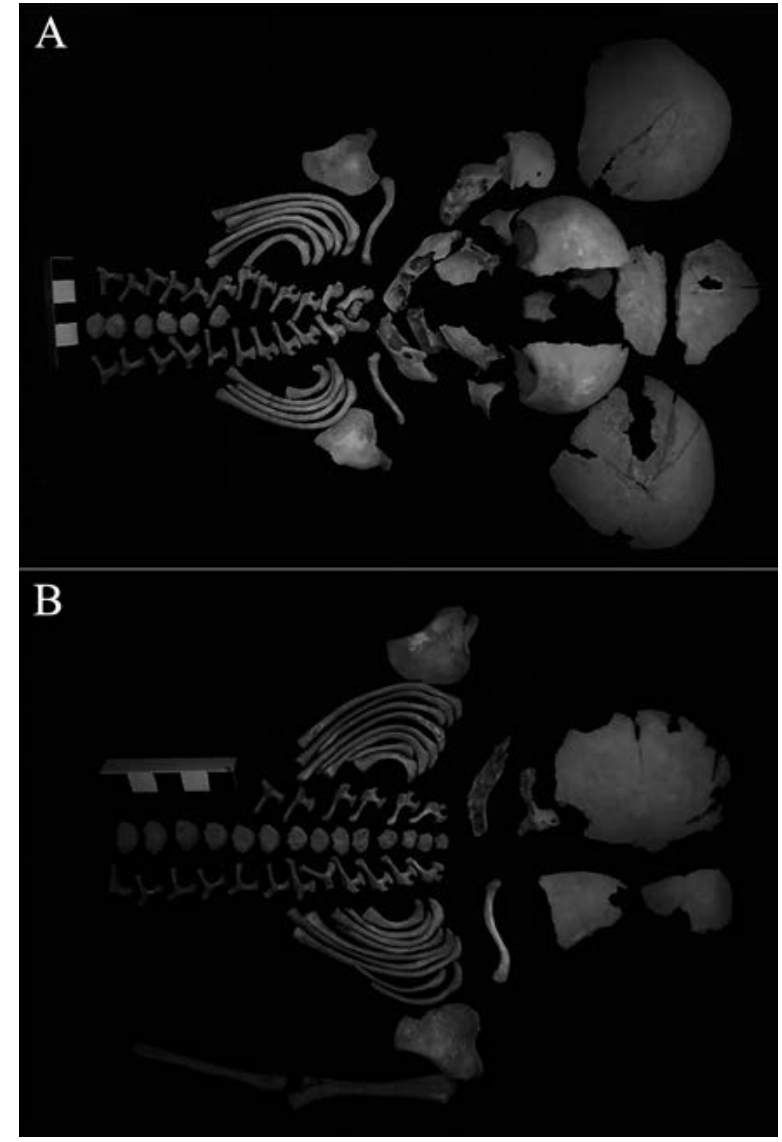

Fig. 7. El Molí d'Espígol (Tornabous, Lérida): Individuos infantiles: A: INDi-6; B: INDi-7.

muy probablemente en una fosa practicada en el nivel de regularización del nuevo piso, que se culminó con un enlosado.

El sector 153 forma parte, junto con los sectores 151 y 152 , de la UH/M 14 del barrio extramuros de la ciudad ibérica, construido durante la ampliación de la ciudad a inicios del período Ibérico Pleno. Cabe inferir de las informaciones proporcionadas por Cura (2006: 3738) que los sectores 153 y 152 fueran los módulos domésticos del complejo UH/M 14, mientras que el 151 podría identificarse con el espacio de almacén individualizado. Así pues, proponemos como hipótesis que el enterramiento proceda de un contexto doméstico.

Los restos del INDi-7 pertenecen a un individuo perinatal ya estudiado por la coautora de este estudio (M.E.S.). Tan solo se han preservado los procedentes de la fracción superior del esqueleto, cráneo, tórax y parte de la extremidad superior izquierda (húmero y cúbito con un índice de preservación del 36,36 \%) (Fig. 7B). La edad se estimó en unas $39 \pm 2$ semanas de gestación a partir de las medidas de los huesos y 
del grado de desarrollo de la única pieza conservada (segundo incisivo deciduo inferior derecho, pieza 82). La morfología de la hemimandíbula conservada no permite la atribución de sexo. No se advierten evidencias patológicas ni tafonómicas.

\subsection{Discusión}

Los restos de individuos adultos son parciales y parecen responder a realidades distintas. Del INDa-1 se conserva un fragmento de hueso largo, seccionado por un objeto cortante de manera perpendicular. Es un corte intencionado ejecutado cuando el individuo aún estaba vivo, o poco después de su muerte, considerado como peri mortem. Además, una vez descarnado y pulido el hueso, se le hicieron incisiones de manera premeditada ya que siguen un patrón concreto. Su significado se nos escapa. Muestra, pues, una cierta "personalización" intencionada, quizá relacionable con algún tipo de uso específico. En cambio, la fractura del cráneo del INDa-2 seguramente es antigua. Muestra claras evidencias de que su parte exterior estuvo expuesta al fuego, pero ni de forma prolongada ni a altas temperaturas, quizá accidentalmente, lo cual descarta una incineración de tipo funerario. La afectación por fuego probaría que, en algún momento, el cráneo o parte de él habría estado expuesto a la intemperie o en el interior de algún recinto, voluntaria o involuntariamente.

En principio, ambos individuos parecen estar descontextualizados. El INDa-1 fue hallado en un depósito de regularización asociado a la segunda fase de construcción de la MUR-1 de la Primera Edad del Hierro. El espacio está fuera del perímetro estricto de la fortaleza, ubicado entre la cortina de las torres T-1 y T-3 y la escarpa del hipotético foso de la MUR-1. No se registraron ni materiales ni estructuras asociadas que aportaran indicios de acciones singulares o rituales. El INDa-2, en cambio, procede de un espacio doméstico del período Ibérico Pleno: la regularización constructiva del piso del sector 156, en su segunda fase. Tampoco el contexto del hallazgo presenta evidencias de singularidad. Ninguno de ellos muestra trazas de cremación intencionada, a la manera de una incineración ritual funeraria.

Así pues, no parece posible asociar los restos ni a espacios ni a prácticas rituales vinculadas a la exposición de partes del cuerpo humano, a la manera que se documenta en contextos ibéricos layetanos e indigetes del nordeste peninsular o de la Galia céltica (Rovira Hortalà 1998; Ciesielski et al. 2011; Gracia 2017: 109156). Destacamos que, a pesar de la diferencia cronológica de los contextos de aparición, ambos restos fueron recuperados en el área nordeste del yacimiento, en espacios relativamente cercanos. Esta área, además, presenta una potente secuencia ocupacional, con importantes movimientos de tierra y una actividad constructiva intensa desde finales del siglo VIII hasta el III a. n. e.

Los siete individuos infantiles tienen una edad en torno a las 38-40 semanas de gestación y, por tanto, probablemente nacieron. El sexo se ha podido establecer en tres casos: dos niñas y un niño. Una de las niñas presentaba periostitis, así como también el INDi-1 de sexo desconocido. Como no todos los individuos presentan periostitis se excluye una interpretación poblacional relacionada con la naturaleza del agua y su influencia en el desarrollo óseo. La periostitis de ambos individuos pudo deberse a un proceso infeccioso crónico de transmisión materna a lo largo del crecimiento embrionario. Ello no asegura que esta fuera la causa de su muerte. En todo caso, la mortalidad del resto de individuos a tan temprana edad podría deberse a un proceso infeccioso agudo, o a las dificultades entorno del parto.

Los datos arqueológicos indican que INDi-2, INDi-5, INDi-6 y INDi-7 son deposiciones primarias. Todos los individuos tienen un índice de preservación que supera el $30 \%$, aunque el mejor conservado, el INDi-2, es el excavado más recientemente. La localización del INDi-3 no es primaria. Se recuperó en un depósito alterado por remociones llevadas a cabo en su contexto original. Las marcas de mordeduras se documentan en el INDi-2 pero en ninguna otra deposición primaria. Ello indica el cuidado con que se enterraron los cuerpos, colmatados de tierra para dificultar el acceso de la microfauna. Las marcas de mordedura en los INDi-1, INDi-3 y INDi-4 podría indicar un tipo de inhumación o de ritual de deposición ligeramente distinto: quizá los restos se depositasen en una fosa cubierta por una losa, lo cual mantuvo un espacio vacío; o el cuerpo no dispusiera de mortaja.

La horquilla cronológica del conjunto de individuos se sitúa entre la Primera Edad del Hierro y el período Ibérico Pleno. Al menos uno es adscribible a cada gran período: dos a la Primera Edad del Hierro, uno al período Ibérico Antiguo y cuatro al Ibérico Pleno. Siete infantes fallecidos a lo largo de unos 500 años, no se ajusta a los altos índices de mortalidad infantil que los estudios demográficos plantean para comunidades premodernas y prehistóricas (Livi-Bacci 1993: 165-173). Es decir, si las inhumaciones perinatales de El Molí d'Espígol respondiesen a una dinámica funeraria que afectase a la totalidad de la población del sitio, cabría esperar un mayor número de enterramientos incluso a pesar de que el yacimiento no ha sido excavado en su totalidad.

Los identificados como deposiciones primarias responden al patrón ritual general que se documenta en 
contextos preibéricos e ibéricos del nordeste peninsular y de la Galia meridional (Belarte y Sanmartí 1997: 12; Belarte y de Chazelles 2011: 186): inhumaciones en fosa bajo piso de espacio habitacional/trabajo/polivalente, y sin ajuar. En ningún caso se han detectado enterramientos múltiples. Tampoco se observa un área de concentración de restos, más allá de las dos inhumaciones halladas en el sector 64/65 del ES-A. Aquí hay ciertos indicios de singularidad que le han otorgado un sentido "ideológico" dentro del conjunto del ES-A (cf. supra). El contexto de aparición del INDi-1, de la Primera Edad del Hierro indica un ambiente, en principio, doméstico aunque existe un hogar en forma de lingote chipriota en el mismo espacio.

\section{RESTOS HUMANOS EN ÁMBITO ILERGETE}

El elenco de restos humanos, sin distinción, hallados en espacios de hábitat dentro del territorio histórico atribuido al pueblo ilergete es, a día de hoy, notable. Notable si se considera que, en su mayoría, son inhumaciones infantiles y que las evidencias de individuos adultos son escasas. Los estudios que han ido tratando ambos grupos de evidencias muestran claramente que responden a casuísticas distintas, sin conexión directa más allá del hecho que, en principio, ambos casos serían acciones rituales, siendo los restos humanos el vehículo del ritual. Por un lado, las inhumaciones infantiles afectan a un grupo de edad muy concreto (individuos perinatales), se presentan de cuerpo entero, como una unidad (en deposiciones individuales o más raramente múltiples), sin selección de sus partes. Son manifestaciones que se mantendrían mayoritariamente dentro de una esfera privada para unos (Dedet 2008: 132-134), mientras otros también sugieren alternativas en relación con un ritual colectivo (cf. Nieto 2013: 138).

La razón y causa de tales prácticas continúa generando controversia. Unas hipótesis las consideran infanticidios rituales o sacrificios voluntarios. En otras la muerte por causa natural a temprana edad, sin haber accedido plenamente aún al cuerpo social les habría negado o bien recibir sepultura en necrópolis a la manera reservada a los miembros adultos de la comunidad; o bien haber sido objeto de rituales propiciatorios con un sentido profiláctico por razón de su muerte, los cuales conllevaban la renovación/transformación de espacios domésticos, o incluso productivos (Belarte y Sanmartí 1997: 24-26; Gusi y Muriel 2008: 260-261 y 288-302; Belarte y de Chazelles 2011: 185). Sea cual fuera la explicación de tal práctica, parece evidente que se trataría de acciones excepcionales, con una importante carga social diacrítica, que se escapan de la dinámica funeraria generada por los altos índices de mortalidad infantil supuestamente atribuibles a las sociedades protohistóricas (Guérin y Martínez Valle 1987-1988; Belarte y Sanmartí 1997: 25; Agustí et al. 2000: 319-321; Dedet 2008: 10-14 y 73; Gracia 2017: 133): solo algunos perinatales muertos, de manera específica, eran enterrados en espacios domésticos. Probablemente, y dado que no se conocen tumbas infantiles en las necrópolis ni de la Primera Edad del Hierro ni de época ibérica en el noreste (Agustí et al. 2000: 317-319), la mayoría de los cadáveres serían simplemente expuestos o abandonados (Agustí et al. 2000: 319; Dedet 2008: 137).

Su larga perduración en el tiempo podría haber comportado una evolución del ritual o de su mismo sentido, que se habría plasmado en la transformación, sustitución o combinación de tales prácticas con sacrificios de animales (Gusi y Muriel 2008: 308-309; Nieto 2013). Por otra parte, los casos de concentración de enterramientos en determinadas estancias, ha llevado a otorgarlas algún tipo de significación excepcional, al menos en el círculo familiar donde tendría lugar el ritual (Belarte y Sanmartí 1997: 25).

Los restos de adultos corresponderían a individuos jóvenes o de mediana edad. Hay una clara selección de las partes del cuerpo, por lo general, cabezas pero también, y de manera más excepcional, miembros que tradicionalmente se han venido a interpretar como trofeos de guerra, los restos de enemigos muertos durante alguna acción bélica. Su hallazgo en contextos de hábitat documentaría rituales de exposición con un claro componente ideológico de exaltación de determinadas familias, pero que también se relacionaría con la veneración a los antepasados mediante la alabanza de sus gestas (García Jiménez 2006: 88-90; Ciesielski et al. 2011: 134-139; Armit 2012: 118-119 y 222-223; Gracia 2015; Rovira Hortalà y Codina 2015; Subirà y Rovira Hortalà 2019). Su espacio social sería el de la esfera pública.

La práctica ritual de las inhumaciones infantiles es un elemento recurrente y común a todas las comunidades ibéricas de la cuenca mediterránea occidental, desde Andalucía hasta el Languedoc. Sin embargo, en relación con la cultura ibérica, el hallazgo de partes del cuerpo de individuos adultos es una característica propia de los pueblos septentrionales, de ámbito catalán y languedociense. Dentro del ámbito catalán, quedan restringidos a las comunidades iberas de la costa central (Layetanos) y septentrional (Indigetes), cuyos vínculos culturales con el área gala parecen más estrechos (Sanmartí 1994; Belarte y Sanmartí 1997: 27).

El área histórica ilergete (cuencas Segre y Cinca, depresión central catalana grosso modo) es bastante prolija en inhumaciones infantiles. El registro es bas- 


\begin{tabular}{|c|c|c|}
\hline PERÍODO & Sitios Segre-Cinca & Sitios DCC-LU \\
\hline Bronce Medio & La Pedrera (1) & El Tossal de les Tenalles (1) \\
\hline Bronce Final & $\begin{array}{c}\text { La Pedrera (3) } \\
\text { Azafranales (1) } \\
\text { Carretelà (1) } \\
\text { Vincamet (1) }\end{array}$ & $\begin{array}{c}\text { Els Vilars (13) } \\
\text { Eolí d'Espígol (2) }\end{array}$ \\
\hline Primera Edad del Hierro & La Codera (1) & Els Vilars (11) \\
\hline Ibérico Antiguo & La Serra del Calvari (1) & Molí d'Espígol (1) \\
\hline Ibérico Pleno & & Els Vilars (1?) \\
& & Els Estinclells (1) \\
\hline Ibérico Tardío & & Eolí d'Espígol (4) \\
\hline
\end{tabular}

Tab. 2. Comparación de las inhumaciones infantiles en el territorio considerado (yacimientos protourbanos/urbanos y períodos). DCC-LU depresión central catalana-llanura Urgell.

tante temprano en la zona del Segre-Cinca, en contextos protourbanos y urbanos: los primeros ejemplos podrían remontarse al Bronce Medio (Grupo Segre I), como el del poblado de La Pedrera (Vallfogona de Balaguer, Lérida) (Anfruns et al. 1989; Gallart y Junyent 1989: 56-60). Al Bronce Final (Grupo Segre II) se asignan los tres enterramientos documentados en el estrato VII de La Pedrera (Anfruns et al. 1989; Gallart y Junyent 1989: 52), así como las inhumaciones de Azafranales (Fraga, Huesca) (Maya 1986: 45), Carretelà (Aitona, Lérida) (González Pérez et al. 1983: 173), El Tossal de les Tenalles (Sidamon, Lérida) (Campillo 1993; Garcés et al. 1993) y Vincamet (Fraga, Huesca) (Moya et al. 2005: 41-42). A partir de la Primera Edad del Hierro el elenco se reduce a los restos de El Molí d'Espígol (cf. supra), a los hallazgos de perinatales en Els Vilars (Agustí et al. 2000; Moya et al. 2005: 41, n. 24; Alonso et al. 2020: 108), otro en La Serra del Calvari (La Granja d'Escarp, Lérida) (Vàzquez Falip et al. 2014: 216), así como a la sepultura múltiple de La Codera (Alcolea de Cinca, Huesca) en la transición hacia el período Ibérico Antiguo (Blasco y Montón 2019).

Las inhumaciones perinatales ya durante el período Ibérico Antiguo están representadas sólo en Els Vilars y El Molí d'Espígol ( $c f$. supra), mientras que en período Ibérico Pleno de nuevo en El Molí d'Espígol ( $c f$. supra), Els Vilars y en el poblado de Els Estinclells (Verdú, Lérida) (Muriel et al. 2006). Por último, hay que mencionar el hallazgo de un perinatal para el período Ibérico Tardío/Tardorrepublicano (siglos II-I a. n. e.) en el yacimiento de La Rosella (Tárrega, Lérida) (Escala et al. 2011: 222; Armentano 2020: 289-292).

En conjunto, las inhumaciones son individuales de manera mayoritaria. Los ejemplos de enterramientos múltiples se documentan, sobre todo, en cronologías preibéricas (e. g. La Codera o Els Vilars) y, seguramente, son muertes simultáneas en un mismo contexto doméstico. No se detecta presencia de ajuares, más allá de algún caso de probable ofrenda animal (e. $g$. Tossal de les Tenalles o La Codera) o de pequeño mobiliario (e. g. La Serra del Calvari o Els Vilars), todos relacionados con cronologías preibéricas. De hecho, la primera inhumación de La Pedrera, la más antigua conocida en el valle del Ebro en contexto protourbano, se escapa del ritual generalizado y común para estas prácticas por haberse realizado en una urna cerámica y no directamente en fosa. La elevada datación de esta inhumación, junto a las precedentes de la Edad del Bronce de Minferri (Juneda, Lérida) y Cantorella (Maldà, Lérida) (Alonso et al. 2020: 108), ha llevado incluso a proponer que fuera una práctica autóctona en la zona ${ }^{5}$, dado que tradicionalmente la aparición de las inhumaciones infantiles en contextos de hábitat se asociaba al horizonte de los Campos de Urnas (Agustí et al. 2000: 317; Moya et al. 2005: 41-42).

El análisis de la localización de los yacimientos con inhumaciones perinatales por zona y período (Tab. 2) muestra su concentración, durante el Bronce Medio y Final en el área Segre-Cinca salvo el caso de El Tossal de les Tenalles. En cambio, a partir de la Primera Edad del Hierro las evidencias se van desplazando hacia el este, con ejemplos tanto en el área Segre-Cinca como en la depresión central catalanallanura Urgell. A lo largo del Bronce Medio y Final se detectan inhumaciones en seis yacimientos, ningu-

\footnotetext{
5 J. B. López Melcion, "L'evolució del poblament protohistòric a la plana occidental catalana. Models d'ocupació del territori i urbanisme". Tesis doctoral inédita. Universitat de Lleida. Lérida 2000: 557.
} 
no con más de tres individuos por sitio/período; en la Primera Edad del Hierro se identifican en cuatro con un índice de frecuencia ya superior. A partir del período Ibérico, se limitan a la depresión central catalanallanura Urgell con un aumento notable del número de inhumaciones, concentradas en unos pocos yacimientos (máximo tres, durante el Ibérico Pleno). Así pues, y en función de los mínimos datos disponibles hasta el momento procedentes de espacios protourbanos y urbanos, parece como si dicha práctica progresase, con el paso del tiempo, de un espacio "nuclear" centrado en las cuencas del Cinca-Segre hacia la llanura levantina, más allá del Segre. Curiosamente, a partir del período ibérico no se detectan inhumaciones infantiles en los yacimientos del área Segre-Cinca ni en lo que vendría a ser el territorio occidental ilergete en general. En las cronologías más antiguas, la presencia de inhumaciones por yacimiento es menor, pero están dispersas en diferentes sitios. En cambio, durante el período ibérico parecen concentrarse a una zona y en unos pocos yacimientos. Igualmente hay que señalar que la mayoría de los yacimientos con cronologías más antiguas y inhumaciones infantiles del área Cinca-Segre no llegan al período ibérico.

Els Vilars es el sitio en que se han detectado más inhumaciones hasta el momento con 25 , casi la mitad en niveles del período Ibérico (Alonso et al. 2020: 108). Ello lo sitúa como el yacimiento ibérico con mayor representación de enterramientos infantiles en el área ilergete durante dicho período. Le sigue El Molí d'Espígol con siete, cuatro de ellas adscribibles al Ibérico Pleno, lo cual hace de este yacimiento el sitio con mayor número de inhumaciones perinatales del Ibérico Pleno en el área ilergete. Sin embargo, tales datos deben ser matizados por las características de ambos sitios. Els Vilars es una fortaleza de dimensiones modestas, fosilizada desde la Primera Edad del Hierro (se abandona a inicios del Ibérico Pleno), y completamente excavada (Junyent y López Melcion 2016). Del Molí d'Espígol, un asentamiento más extenso y de mayor entidad, apenas se ha excavado un tercio. Els Vilars y El Molí d'Espígol son yacimientos donde el ritual de las inhumaciones infantiles se practica durante todo su período de vida con ejemplos desde época preibérica, cuando se fundan ambos hábitats, hasta el período Ibérico. Por último, son interesantes casos como el de La Rosella donde hay todavía inhumaciones infantiles en contextos del Ibérico Tardío. O incluso más al norte, en el valle del Ebro, en torno al cambio de era, en la colonia romana de Celsa (Velilla de Ebro, Zaragoza) (Mínguez 1990). Sin embargo, el ejemplo más contundente de la perduración de estas prácticas en la zona hasta avanzada la época imperial son las 10 inhumaciones infantiles excavadas en los niveles correspondientes a los siglos I-II d. n. e. del edificio del Antic
Portal de Magdalena, en la Ilerda romana (Lorencio et al. 1998).

La observación diacrónica de las evidencias no parece mostrar un patrón de agrupación en contextos especiales dentro de los yacimientos, sino que las inhumaciones se dan en ámbitos domésticos de manera general. Sin embargo, hay que destacar la singularidad y concentración de los depósitos de Els Vilars durante la Primera Edad del Hierro y el período Ibérico. Su zonificación en el mismo yacimiento y su combinación complementaria con otros depósitos rituales de fauna ha llevado a proponer a Nieto (2013: 156-158) que se tratara de rituales específicos en función de la clase social que habitaba cada barrio, del valor simbólico y de los atributos económicos otorgados al muerto. Según dicha autora, la originalidad de tales prácticas podría ser incluso un hecho diferencial por comparación a las poblaciones iberas de la costa catalana (Nieto 2013: 158). Esta hipótesis harto atractiva, susceptible de mostrar un componente étnico distintivo del área ilergete (al cual incluso se podrían sumar las reflexiones sobre la exposición de restos de cadáveres de adultos, $c f$. infra), requiere contrastarse en otros hábitats del ámbito territorial ilergete.

Como se indicó, en El Molí d'Espígol, durante la Primera Edad del Hierro, se hallaron restos de un perinatal en la HAB-8, una estancia con un hogar en forma de lingote chipriota, elemento al que se atribuye un sentido ritual (Belarte e. p.), asociado, en algunos casos, a recintos de carácter cultual, como sucede en Els Vilars (Junyent y López Melcion 2016: 50 y 79). Además, en El Molí d'Espígol había dos enterramientos reunidos, curiosamente de un niño y una niña, datados en el período Ibérico Pleno, en un espacio singular, el sector 64/65 del ES-A.

Los restos de individuos adultos no están registrados en contexto de hábitat en el territorio ilergete, salvo los documentados en El Molí d'Espígol ${ }^{6}$. Ya hemos visto que hay indicios importantes para considerar que tales restos no se encontraron en su contexto primario.

Fueron trasladados a los emplazamientos donde fueron hallados (un relleno constructivo y un contexto doméstico), quizá de manera involuntaria, con motivo de alguna actividad constructiva llevada a cabo en su emplazamiento original (desconocido). Pero entonces, ¿cómo entender su presencia?

Las hipótesis que actualmente se barajan para explicar la aparición "descontextualizada" de restos aislados de partes del cuerpo en espacios domésticos protohistóricos siguen dos líneas: una la despojaría de

\footnotetext{
${ }^{6}$ Recientemente se ha dado a conocer un probable hallazgo de cráneos en Palau d'Anglesola (Lérida) (Garralón 2020), cuya fiabilidad resulta harto dudosa.
} 
cualquier sentido ritual e ideológico y otra, por el contrario, la contactaría con prácticas rituales o con un sentido mágico. Según la primera, en el lugar del hallazgo, podría haber existido previamente una necrópolis o un espacio de exposición de cadáveres. Al producirse la cancelación, amortización o destrucción del sitio y la construcción del espacio de hábitat posterior en la misma ubicación, algunos restos humanos aislados habrían quedado atrapados en la sedimentación de las regularizaciones constructivas. Serían "contaminaciones" que no se hallarían en contextos primarios (Dedet y Schwaller 1990: 150; Rousseau 2010: $182-183)^{7}$. En la segunda hipótesis tales restos serían reliquias o talismanes, ofrendas puntuales o incluso parafernalia de ceremonias de necromancia o brujería (Dedet y Schwaller 1990: 150; Belarte y de Chazelles 2011: 187). Otras líneas interpretativas que habría que tener en cuenta ven la aparición de restos humanos, relacionados con hábitats o estructuras asociadas, como muestras de la denominada "mala muerte". Serían personas ajenas al contexto social, víctimas de algún castigo u otro suceso especialmente negativo (enfermedad, accidente) por los cuales el individuo quedaba fuera del espacio social común, excluido del trato funerario general del grupo. Tras su muerte serían abandonadas o arrojadas en espacios de vertedero o basurero (normalmente silos en proceso de amortización), como cualquier otro despojo (Oliver 2004; Gracia 2017: 134135). Incluso, aunque es bastante difícil de sustentar, se han sugerido prácticas relacionados con el canibalismo (Dedet y Schwaller 1990: 149).

El Molí d'Espígol carece de evidencias que permitan decantarnos de manera inequívoca en una $\mathrm{u}$ otra dirección, ni a partir del estudio de los propios restos, ni de su contexto de aparición. Faltan indicios de necrópolis en el lugar, si bien en el área de aparición de los restos, en conjunto, la actividad constructiva fue intensa con diversas remodelaciones ya desde fases muy tempranas de la Primera Edad del Hierro. Desconocemos la fisonomía de los espacios extramuros de la fortaleza en su fase inicial. Los únicos restos documentados son ya de la segunda fase de remodelación de la muralla MUR-1: un posible foso y un posible "santuario" con betilos delante de la torre T-4 (cf. supra), próximos a la zona de los hallazgos. No es imposible que hubiera una necrópolis cercana al recinto de la fortaleza, dado que se conocen ejemplos de hábitat y necrópolis en el contexto cronocultural del Grupo Segre-Cinca durante la Primera Edad del Hierro

\footnotetext{
7 Una hipótesis en esta línea podría explicar la presencia de restos humanos descontextualizados aparecidos en los niveles correspondientes al Ibérico Tardío/época Tardorrepublicana (siglos II-I a. n. e.) del Antic Portal de Magdalena, en la ciudad de Lérida (Puig y Lázaro 1986: 84; Loriente y Oliver 1992: 27-28).
}

(Vàzquez Falip 2000). El ritual se relaciona con la cremación de los restos en ustrinum y su posterior selección antes de la deposición (Vàzquez Falip 2000: 93). Tal ritual, propio de la Primera Edad del Hierro, es incompatible con los restos humanos de El Molí d'Espígol, cuyo análisis ha constatado la falta de cualquier rastro de cremación. Así pues, su contexto primario no sería, en principio, funerario. Si considerásemos la existencia de áreas de exposición de cadáveres, tal hipótesis podría ser plausible para el fragmento craneal, aún sin evidencias concluyentes.

El contexto de aparición de INDa-1 no resulta propicio a priori a la hipótesis de que se pudiera tratar de reliquias o talismanes al ser un nivel de relleno constructivo de la cortina de la MUR-1, en un espacio exterior a la muralla. Sin embargo, la opción de una reliquia o talismán cobra fuerza si su presencia en solitario no responde ni a una "contaminación" habilitada por la cancelación de un conjunto funerario precedente, ni a su pertenencia a un conjunto más complejo de ofrendas o situable en un espacio ritual; de igual manera, los cortes post mortem que presenta, completamente intencionales y siguiendo un patrón evidente reforzarían esa idea. Claramente se trata de un contexto secundario, difícil de evaluar, pero que podría relacionarse con algún tipo de desecho, desuso o incluso pérdida (intencional o impremeditada) de una reliquia o talismán.

El contexto de aparición del fragmento de cráneo INDa-2 apunta que no estaríamos ante un caso de exposición de "cabezas cortadas" del tipo documentado en el área layetano-indigete. Tampoco parece plausible la idea de un espacio funerario precedente, tipo necrópolis de incineración, cancelado. Los restos de alteración térmica en su superficie exterior vendrían a indicar su exposición fortuita al fuego. ¿Podría haber estado expuesto de manera ritual en un lugar afectado por un incendio y que, en la reestructuración posterior de la zona se produjese una cancelación y amortización del espacio con la pérdida, extravío o destrucción de los restos humanos expuestos? Tal acción implicaría una desacralización del espacio y también de los restos, que habrían sido desechados. Ello podría corresponderse bastante bien con la presencia de una pieza aislada, olvidada, en un depósito de regularización.

\section{CONCLUSIONES}

Las evidencias presentadas en este trabajo hacen emerger a El Molí d'Espígol como el asentamiento protohistórico con mayor combinación de restos humanos del área ilergete.

Es el único sitio en que se han documentado restos de adultos, aunque su significado no parece correspon- 
derse con el sentido ritual que muestran en las áreas de mayor concentración del mundo ibérico septentrional layetano-indigete. Su hallazgo parece fruto de acciones involuntarias, de contaminaciones en contextos secundarios, que no revisten ningún tipo de significación ideológica. Se nos escapa la que podrían haber tenido previamente en un contexto primario, relacionable con algún tipo de espacio ideológico (¿santuario?) o funerario. No aparecen restos de adultos en contextos de hábitat protohistóricos de la Primera Edad del Hierro y del período Ibérico de la Cataluña occidental, ni en el área aragonesa oriental vinculada al territorio histórico de los Ilergetes. Ello sumado a la nula entidad ideológica atribuible a los de El Molí d'Espígol a partir de sus contextos de aparición, nos lleva a plantear la hipótesis de que la exposición ritualizada de partes del cuerpo humano en espacios urbanos de alto significado simbólico podría no haberse dado en el mundo ibérico ilergete. Cabe plantearlo al menos durante el período Ibérico Pleno, al contrario de lo que se observa en el área layetano-indigete, que parece mostrar vínculos culturales más estrechos con el área gala. Posiblemente la ausencia de tal práctica debiera relacionarse con otras estrategias de afirmación de la aristocracia ilergete desconectadas del ascendiente galo. Existen, en el ámbito histórico ilergete, indicios indirectos interpretables en clave de amputación/exposición de miembros o partes del cuerpo, vinculados a la exaltación de gestas guerreras como las manos cortadas representadas en la estela de La Vispesa (Tamarite de Litera, Huesca) (Marco y Baldellou 1976; Garcés 2007). No obstante, no hay evidencias para pensar que tales manos estuviesen expuestas en espacios de hábitat (tampoco se han detectado restos de manos en espacios de hábitat ilergetes) y tampoco se representan cabezas cortadas en las estelas hasta el período Ibérico Tardío. Así pues, no parece haber conexión entre esta representación iconográfica ya tardía, y la práctica de exposición de las "cabezas cortadas" en sentido general, como se presenta en las áreas layetano-indigete y languedociense. En cualquier caso, la ausencia de esta práctica en el área ilergete vendría a reforzar la idea de una diferenciación cultural entre los pueblos iberos de la zona costera catalana (al menos central y nororiental) y del interior.

Las inhumaciones de los individuos infantiles de El Molí d'Espígol son las típicas en contextos domésticos o de trabajo. Las evidencias parecen apuntar hacia diferentes tipos de rituales de deposición del cuerpo y a la indefinición de un patrón relativo a las características morfológicas o de relevancia social del lugar o contexto del enterramiento. No se trataría de un ritual socialmente generalizado sino más bien con un cierto significado diacrítico que afectaría a determinadas familias. Lo reducido de la muestra y la im- posibilidad de concretar el sexo de los restos impide sacar conclusiones sobre si hay una selección sexual de los individuos. No contamos con datos del todo concluyentes pero la causa de la muerte de los infantes parece haber sido natural. En este sentido, el mundo ilergete parece seguir las líneas generales apuntadas en otros hábitats de la zona desde prácticamente el Bronce Final hasta el período Ibérico Tardío, casi extensibles a todo el mundo ibérico septentrional.

\section{BIBLIOGRAFÍA}

Agustí, B.; Alonso, N.; Garcés, I.; Junyent, E.; Lafuente, A. y López Melcion, J. B. 2000: "Una inhumación múltiple de perinatales en la fortaleza de Els Vilars (Arbeca, Lleida) y las prácticas de enterramiento en hábitat durante la primera Edad del Hierro en el valle del Segre (Catalunya)". En B. Dedet, Ph. Gruat, G. Marchand, M. Py y M. Schwaller (eds.): Archéologie de la Mort, Archéologie de la Tombe au Premier Âge du Fer. Monographies d'Archéologie Méditerranéenne 5, UMR 154-CNRS. Lattes: 305-324.

Alonso, N.; Bernal, J.; Castellano, A.; Escala, O.; González, S.; Junyent, E.... y Vila, S. 2020: "La fortalesa dels Vilars (Arbeca, Les Garrigues) durant l'ibèric antic (550-425 ane)". En M. Torres, I. Garcés y J. R. González (eds.): Projecte Ilergècia: Territori i poblament ibèric a la plana ilergeta. Grup de Recercques de les Terres de Ponent. Guissona: 85-118.

Anfruns, J.; Oms, J. I. y Roca, A. 1989: "Estudi antropològic". En J. Gallart y E. Junyent: Un nou tall estratigràfic a la Pedrera, Vallfogona de Balaguer-Térmens, La Noguera, Lleida. Espai/Temps 3, Quaderns del Departament de Geografia i Història de l'Estudi General de Lleida, Universitat de Lleida. Lérida: 108-120.

Armentano, N. 2020: “Aportacions de l'antropologia biològica a 1'edat del ferro i al món ibèric. El cas de la Rosella i del Molí d’Espígol”. En M. Torres, I. Garcés y J. R. González (eds.): Projecte Ilergècia: Territori i poblament ibèric a la plana ilergeta. Grup de Recercques de les Terres de Ponent. Guissona: 281-296.

Armit, I. 2012: Headhunting and the body in Iron Age Europe. Cambridge University Press. Cambridge.

Belarte, M. C. 1997: Arquitectura domèstica $i$ estructura social a la Catalunya protohistòrica. Arqueomediterrània 1, Universitat de Barcelona. Barcelona.

Belarte, M. C. en prensa: "Forme, fonction et signification des foyers dans la culture ibérique (600-200 av. J.-C.)". En Actes de la Table Ronde Autour du Foyer (París 2019). Carnet de recherche des projets collectifs ArScAn. Maison de l'Archéologie et de l'Ethnologie. París.

Belarte, M. C. y de Chazelles, C. A. 2011: "Les manifestations de pratiques rituelles en contexte domestique en Ibérie et en Gaule méditerranéenne". En R. Roure y L. Pernet (eds.): Des rites et des hommes. Les pratiques symboliques des Celtes, des Ibères et des Grecs en Provence, en Languedoc et en Catalogne. Errance. París: 165-188.

Belarte, M. C. y Sanmartí, J. 1997: "Espais de culte i pràctiques rituals a la Catalunya protohistòrica". Quaderns de Prehistòria i Arqueologia de Castelló 18: 7-32.

Blasco, M. F. y Montón, F. J. 2019: "Enterramientos perinatales de la Primera Edad del Hierro en el poblado de La Codera (Alcolea de Cinca, Huesca)". Bolskan 27: 41-45.

Campillo, D. 1993: "Un esquelet infantil del Tossal de les Tenalles (Sidamon)". En J. Padró, M. Prevosti, M. Roca y J. Sanmartí (eds.): Homenatge a Miquel Tarradell. Estudis Universitaris Catalans XXIX, Curial Edicions Catalanes. Barcelona: 535-536.

Campillo, D. y Subirà M. E. 2004: Antropología Física para Arqueólogos. Ariel. Barcelona.

Ciesielski, E.; Duday, H.; Girard, B.; Roure, R.; Martín A. y Agustí B. 2011: "La pratique des têtes coupées et les dépôts d'armes en Gaule méditerranéenne et dans le nord de la Péninsule Ibérique". En R. 
Roure y L. Pernet (eds.): Des rites et des Hommes. Les pratiques symboliques des Celtes, des Ibères et des Grecs en Provence, en Languedoc et en Catalogne. Errance. París: 113-145.

Crétot, M. 1978: L'arcade dentaire humaine. Morphologie. Julien Prélat. París.

Cura, M. 1989: “Enterraments infantils al Molí d'Espígol de Tornabous (Urgell, Lleida)". Cuadernos de Prehistoria y Arqueología Castellonenses 14: 173-182.

Cura, M. 2006: El jaciment del Moli d'Espigol (Tornabous-Urgell): excavacions arqueologiques 1987-1992. Museu d'Arqueologia de Catalunya. Barcelona.

Dedet, B. 2008: Les enfants dans la société protohistorique. L'exemple du Sud de la France. Collection de l'École Française de Rome 396, École Française de Rome. Roma.

Dedet, B. y Schwaller, M. 1990: "Pratiques cultuelles et funéraires en milieu domestique sur les oppidums languedociens". Documents d'Archéologie Méridionale 13: 137-161.

Escala, O.; Moya, A.; Piqué, G.; Principal, J.; Tartera, E. y Vidal, A. 2016: "Darreres intervencions al Molí d'Espígol (Tornabous, Urgell). El projecte de 1,1\% cultural: l'excavació arqueològica i els treballs de consolidació i restauració del jaciment". Tribuna d'Arqueologia 2014-2015: 267-303.

Escala, O.; Moya, A.; Tartera E. y Vidal, A. 2011: "El jaciment de La Rosella (Tàrrega, Urgell): camp de sitges associat a un hàbitat de l'ibèric tardà (segles II i I a. de la n.e.)". Urtx 25: 211-241.

Fatás, G. 1987: "Apunt sobre els Ilergets i llurs terres occidentals". Fonaments 6: 11-22.

Gallart, J. y Junyent, E. 1989: Un nou tall estratigràfic a la Pedrera, Vallfogona de Balaguer Térmens, la Noguera, Lleida. Quaderns del departament de Geografia i Història de l'Estudi General de Lleida, Universitat de Lleida. Lérida.

Garcés, I. 2007: "Interpretaciones sobre el monumento ibérico de La Vispesa (Tamarite de Litera, Huesca)". Caesaraugusta 78: 337-354.

Garcés, I.; Marí, L.; Puche, J. M. y Sorribes, E. 1993: "Un enterrament infantil al Tossal de les Tenalles (Sidamon, Pla d'Urgell)". En J. Padró, M. Prevosti, M. Roca y J. Sanmartí (eds.): Homenatge a Miquel Tarradell. Estudis Universitaris Catalans XXIX, Curial Edicions Catalanes. Barcelona: 535-536.

García Jiménez, G. 2006: Entre Iberos y Celtas: Las espadas de tipo La Tène del noreste de la Península Ibérica. Anejos de Gladius 10, CSIC. Madrid.

Garralón, S. 2020: "Notícia d'uns cranis enclavats trobats al Palau d'Anglesola (El Pla d'Urgell, Lleida)". En M. Torres, I. Garcés y J. R. González (eds.): Projecte Ilergècia: Territori i poblament ibèric a la plana ilergeta. Grup de Recercques de les Terres de Ponent. Guissona: 407-416.

González Pérez, J. R.; Junyent, E.; Maya, J. L. y Rodríguez, J. I. 1983: "Carretelà, Aitona, Segrià". Arqueología 82. Ministerio de Cultura. Madrid: 173.

Gracia, F. 2015: "Cabezas cortadas y rituales guerreros en la Protohistoria del Nordeste peninsular". En J. Vidal y B. Antela (eds.): Guerra y religión en el Mundo Antiguo. Pórtico. Zaragoza: 25-110.

Gracia, F. 2017: Cabezas cortadas y cadáveres ultrajados. De la Prehistoria al Estado Islámico. Desperta Ferro. Madrid.

Guérin, P. y Martínez Valle, R. 1987-1988: "Inhumaciones infantiles en poblados ibéricos del área valenciana". Saguntum 21: 231-265.

Gusi, F. y Muriel, S. 2008: "Panorama actual de la investigación de las inhumaciones infantiles en la protohistoria del sudoeste mediterráneo europeo". En F. Gusi, S. Muriel y C. R. Olaria (eds.): Nasciturus: infans, puerulus vobis mater terra. La muerte en la infancia. Diputació de Castelló. Castellón: 257-330.

Junyent, E. y López Melcion, J. B. 2016 (eds.): La Fortalesa dels Vilars d'Arbeca. Terra, aigua i poder en el món iber. Museu de Lleida. Lérida.

Kósa, F. 1989: "Age estimation from the fetal skeleton". En M. Yaşar İşcan (ed.): Age markers in the human skeleton. Charles C. Thomas. Springfield, Illinois: 21-54.

Livi-Bacci, M. 1993: Introducción a la demografia. Ariel. Barcelona.

Lorencio, C.; Puig, F. y Julià, M. 1998: "Enterraments infantils a l'edifici imperial de la Magdalena (Lleida)". En M. Mayer, J. M. Nolla y J. Pardo (eds.): De les estructures indígenes a l'organització provincial de la Hispània Citerior. Societat Catalana d'Estudis Clàssics. Barcelona: 299-315.

Loriente, A. y Oliver, A. (eds.) 1992: L'antic Portal de Magdalena. Universitat de Lleida. Lérida.

Marco, F. y Baldellou, V. 1976: "El monumento ibérico de Binéfar (Huesca)". Pyrenae 12: 91-115.

Maya, J. L. 1986: "Incineració i ritual funerari a les valls del Segre i del Cinca". Cota Zero 2: 39-47.

Mercadal, J. O. 1989: "Estudi paleoantropològic dels enterraments infantils del poblat ibèric del Molí d'Espígol (Tornabous, Urgell)". Cuadernos de Prehistoria y Arqueología Castellonenses 14: 183-190.

Mínguez, J. A. 1990: "Enterramientos infantiles domésticos en la colonia Lepida/Celsa (Velilla de Ebro, Zaragoza)". Caesaraugusta 66-67: 105-122.

Monrós, M. 2010: “L’Edifici Singular A de la ciutat ibèrica del Molí d'Espígol (Tornabous, l'Urgell): interpretació i funcionalitat'. Cypsela 18: 209-222.

Moya, A.; López Melcion, J. B.; Lafuente, A.; Rey, J.; Tartera, E.; Vidal, A.... y Sánchez, A. 2005: "El Grup del Segre-Cinca II (1250-950 cal. a.n.e.) a les terres del Baix Cinca: el poblat clos de Vincamet (Fraga, Osca)". Revista d'Arqueologia de Ponent 15: 13-58.

Muriel, S.; Asensio, D.; Cardona, R.; Ferrer, C.; Morer, J.; Pou, J.... y Garcia Dalmau, C. 2006: "Un enterrament infantil al jaciment ibèric dels Estinclells (Verdú, Urgell)". Urtx 19: 41-68.

Nieto, A. 2013: "Porcs, cavalls, ovelles i infants. Noves aportacions a les pràctiques riutals de la fortalesa dels Vilars (Arbeca, les Garrigues)". Revista d'Arqueologia de Ponent 23: 127-162.

Oliver, A. 2004: "Sacrificios y 'mala muerte' en el registro arqueológico de los yacimientos ibéricos". Espacio, Tiempo y Forma 16-17: 391-417.

Principal, J. 2007: “Els orígens preibèrics del Molí d'Espígol (Tornabous, l'Urgell): establiment $\mathrm{i}$ evolució de l'hàbitat durant la primera edat del ferro". Revista d'Arqueologia de Ponent 16-17: 111-128.

Principal, J.; Asensio, D. y Sala, R. 2012: "L'espai suburbà de la ciutat ilergeta del Molí d'Espígol (Tornabous, l'Urgell)". En M. C. Belarte y R. Plana (eds.): El paisatge periurbà a la Mediterrània occidental durant la protohistoria $i$ l'antiguitat. Institut Català d'Arqueologia Clàssica. Tarragona: 165-182.

Principal, J.; Camañes, M. P. y Monrós, M. 2010: "Darreres intervencions arqueològiques a la ciutat ibèrica del Molí d'Espígol (Tornabous, L'Urgell)". Urtx 23: 12-34.

Principal, J.; Escala, O.; Moya, A.; Tartera, E. y Vidal, A. 2019: "El Molí d'Espígol (Tornabous, Catalonia), a capital city for the Ilergetes?" En M. C. Belarte, J. Noguera, R. Plana-Mallart y J. Sanmartí (eds.): Urbanization in Iberia and Mediterranean Gaul in the first millennium BC. Institut Català d'Arqueologia Clàssica. Tarragona: 197-228.

Puig, F. y Lázaro, P. 1986: "Les excavacions a l'Antic Portal de Magdalena: noves dades sobre l'urbanisme antic de la ciutat de Lleida". Tribuna d'Arqueologia 1985-1986: 83-88.

Reimer, P. J.; Bard, E.; Bayliss, A.; Beck, J. W.; Blackwell, P. G.; Ramsey, C. B... y Van der Plicht, J. 2013: "IntCal13 and Marine13 Radiocarbon Age Calibration Curves 0-50,000 Years Cal BP". Radiocarbon 55 (4): 1869-1887.

Rousseau, E. 2010: "Questionnements sur le traitement du corps humain à l'âge du Fer en Gaule". En I. Cartron, D. Castex, M. Charageat, P. Georges y M. Vivas (eds.): De corps en corps. Traitement et devenir du cadavre. Publications de la Maison des sciences de l'homme d'Aquitaine. Burdeos: 163-192.

Rovira Hortalà, M. C. 1998: "L'exhibició d'armes i cranis enclavats en els hàbitats ibers septentrionals". Cypsela 12: 167-82.

Rovira Hortalà, M. C. y Codina, F. 2015: "Caps tallats al sud d'Europa durant l'edat del ferro". En Els caps tallats d'Ullastret. Violència $i$ ritual al món iber. Ajuntament d'Ullastret-Generalitat de Catalunya. Gerona: 49-56.

Sala, R.; Principal, J.; Olmos, P.; Tamba, R. y Garcia, E. 2013: "Multimethod geophysical survey at the Iron Age Iberian site of El Molí d'Espígol (Tornabous, Lleida, Catalonia): Exploring urban mesh patterns using Geophysics". Archaeological Prospection 20 (4): 249-265. 
Salinas de Frías, M. 2010: Los pueblos prerromanos de la península Ibérica. Akal. Madrid.

Sanmartí, J. 1994: "Eléments de type celtique du nord-est de la péninsule Ibérique". Aquitania 12: 336-351.

Sanmartí, J. y Santacana, J. 2005: Els ibers del nord. Dalmau. Barcelona

Scheuer, L. y Black, S. 2000: Developmental Juvenile Osteology. Academic Press. Londres.

Schutkowski, H. 1993: "Sex determination of infant and juvenile skeletons: 1. morphognostic features". American Journal of Physical Anthropology 90: 199-205.

Subirà, M. E. y Rovira Hortalà, M. C. 2019: "Las 'cabezas cortadas' del poblado ibérico del Puig Castellar (Santa Coloma de Gramenet, Barcelona). Datos para una reinterpretación". Trabajos de Prehistoria 76 (2): 286-302. https://doi.org/10.3989/tp.2019.12238
Ubelaker, D. H. 1989: Human skeletal remains. Excavation, analysis, interpretation. Manuals on Archeology 2, Taraxacum. Washington.

Vàzquez Falip, M. P. 2000: "Les necròpolis dels camps d'urnes del bronze, ferro i època ibèrica del Baix Segre. Aspectes cronològics $\mathrm{i}$ rituals". Revista d'Arqueologia de Ponent 10: 65-101.

Vàzquez Falip, M. P.; González Pérez, J. R. y Medina, J. 2014: “El conjunt de La Serra del Calvari (La Granja d'Escarp, El Segrià): un cas singular d'hàbitat des del bronze final a l'època ibèrica". En $X V$ Col-loqui d'Arqueologia de Puigcerdà. La transició bronze final - la edat del ferro en els Pirineus i territoris veïns (Puigcerdà 2011): 213-223. Puigcerdà.

Walker, P. L.; Johnsin J. R. y Lambert, P. M. 1988: “Age and sex biases in the preservation of human skeletal remains". American Journal of Physical Anthropology 76: 183-188. 